\title{
OSTEOTOMY OF THE CALCANEUM FOR PES CAVUS
}

\author{
F. C. DWyer, Liverpool, England
}

Since the publication of my earlier paper (Dwyer 1955) describing the treatment of pes cavus in children by osteotomy of the calcaneum, many more patients have been operated upon and the procedure has been extended to embrace the more severe deformities encountered in older patients. Over five years have now elapsed since the first operation was performed, and the late results indicate that the procedure is sound.

In children pes cavus develops at any time after the age of three, the age of onset depending on whether the condition is idiopathic or neurological in origin. In the earlier stages what is little more than a high arch is well controlled by a metatarsal bar, but in many cases the deformity progresses to embrace the following characteristics: 1) dropping of the forefoot; 2) contracture of the plantar fascia; 3) clawing of the toes and callosity formation; 4) the gradual development of a varus deformity of the heel and forefoot.

It should be appreciated that, contrary to some text-book descriptions and as pointed out by Todd (1935), contracture of the calcaneal tendon is not a usual accompaniment of uncomplicated pes cavus; equinus is confined to the forefoot, and the heel is usually well developed.

Operations such as those described by Steindler (1921), Lambrinudi (1932), Todd (1935) and others for the relief of pes cavus have, on the whole, proved disappointing, especially for well established deformity in adolescents (Fig. 1).

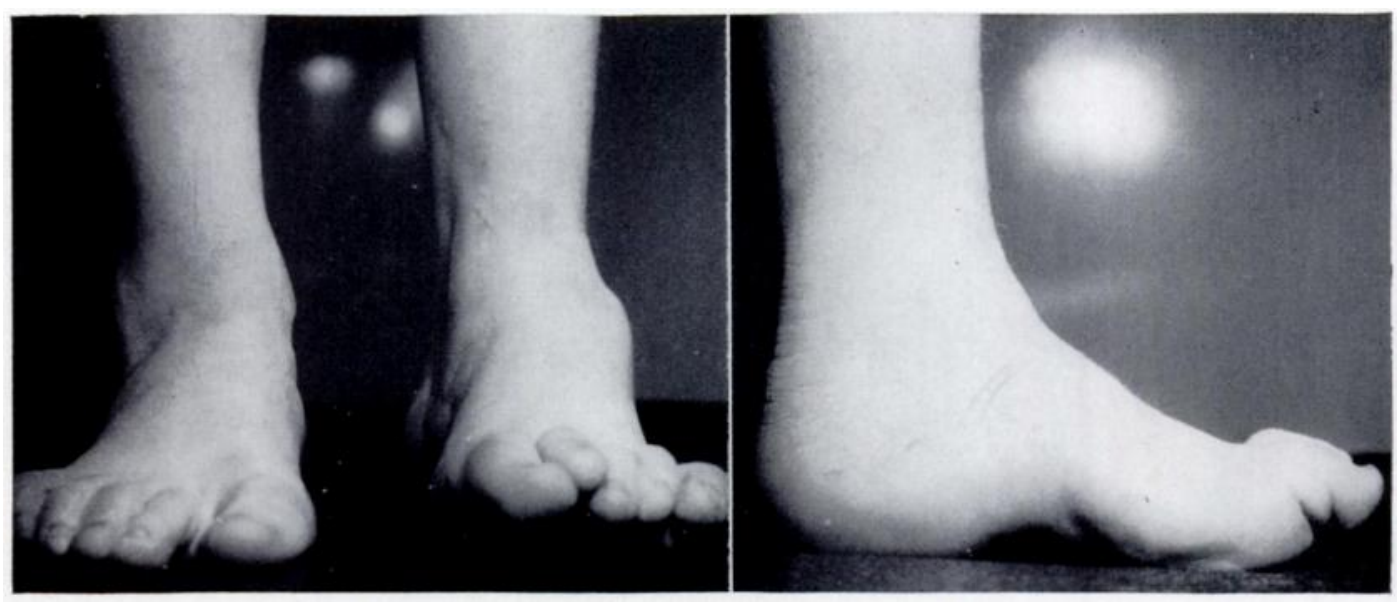

Fig. 1

Pes cavus in a patient aged twelve, two years after a Steindler operation.

Whatever the underlying etiology, it is certain that, with the onset of varus, the deformity rapidly becomes worse. With adduction of the heel three deforming influences appear. First the calcaneal tendon becomes an active invertor and, since its pull is concentrated largely on the inner border of the heel, much of its force is transmitted to the thick medial portion of the plantar fascia (Fig. 2). In consequence the forefoot is pulled towards the heel. Secondly, the child walks on the outer border of the foot, thus increasing the varus deformity. 
Finally, with the heel in varus, weight bearing fails to stretch the plantar fascia and contracture results. The operation that I have described aims at overcoming these deforming influences by shifting the heel into valgus and allowing weight bearing to produce correction.

\section{THE OPERATION}

First the plantar fascia is divided subcutaneously to reduce the obvious dropping of the forefoot. The outer aspect of the calcaneum is then exposed through a curved incision and the whole flap turned forwards until the tendon of the peroneus longus muscle is exposed. The upper and lower surfaces of the bone are cleared. A wedge, with its base eight to twelve millimetres in width, is removed from the calcaneum just below the peroneus longus, which is used as a guide (Fig. 3). This wedge tapers down to the medial cortex, which must be broken to ensure complete closure of the resulting gap.

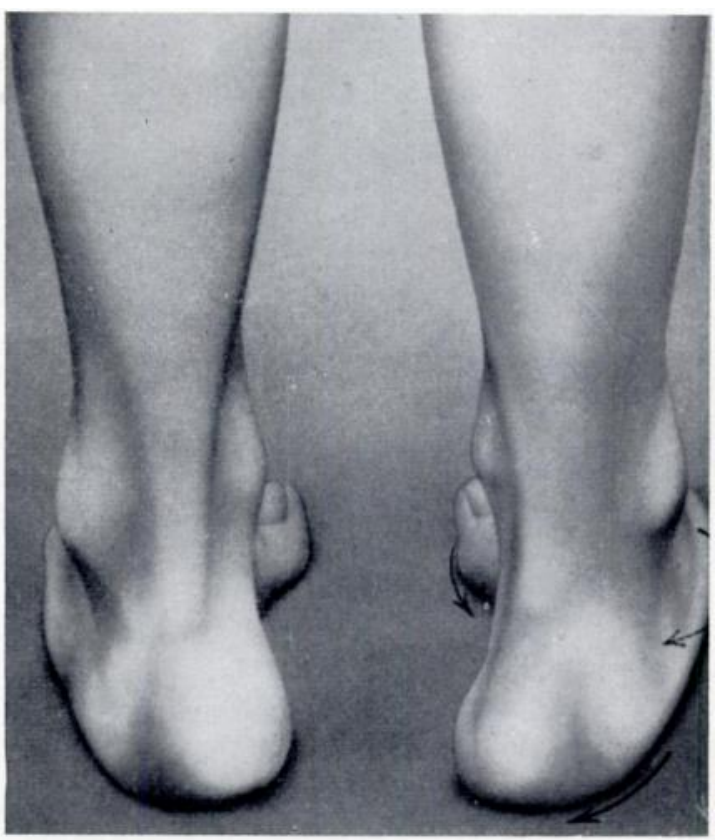

FIG. 2

With inversion of the heel, weight bearing and the pull of the calcaneal tendon become deforming forces, allowing the plantar fascia to contract with resultant approximation of heel and forefoot.

Pressing the forefoot up into dorsiflexion

against the pull of the calcaneal tendon brings the bony surfaces together nicely. Failure to obtain closure is invariably due to leaving a small piece of the apex behind. (It is important

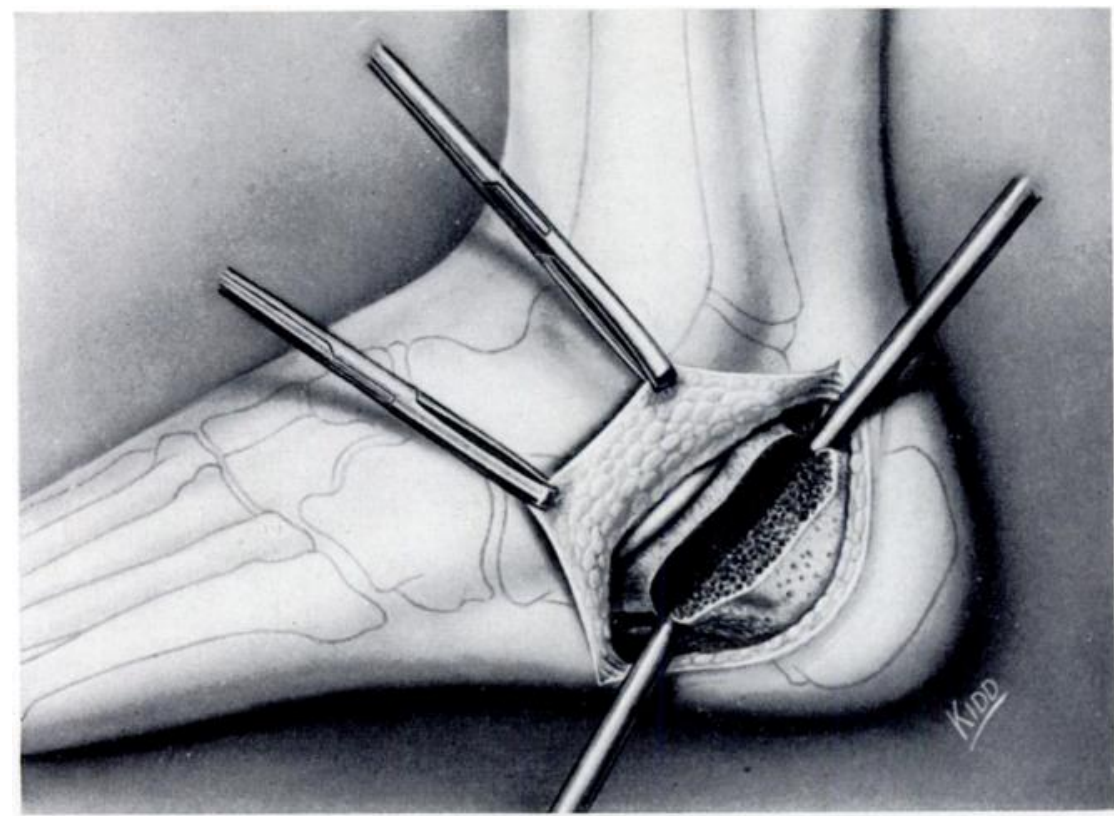

Fig. 3

Technique of operation. A wedge is removed from the lateral aspect of the calcaneum. The osteotomy is made just below the peroneus longus tendon and the posterior talocalcaneal joint. The medial cortex must be cracked to allow the distal fragment to close easily.

VOL. 41 B, NO. 1, FEBrUARY 1959 


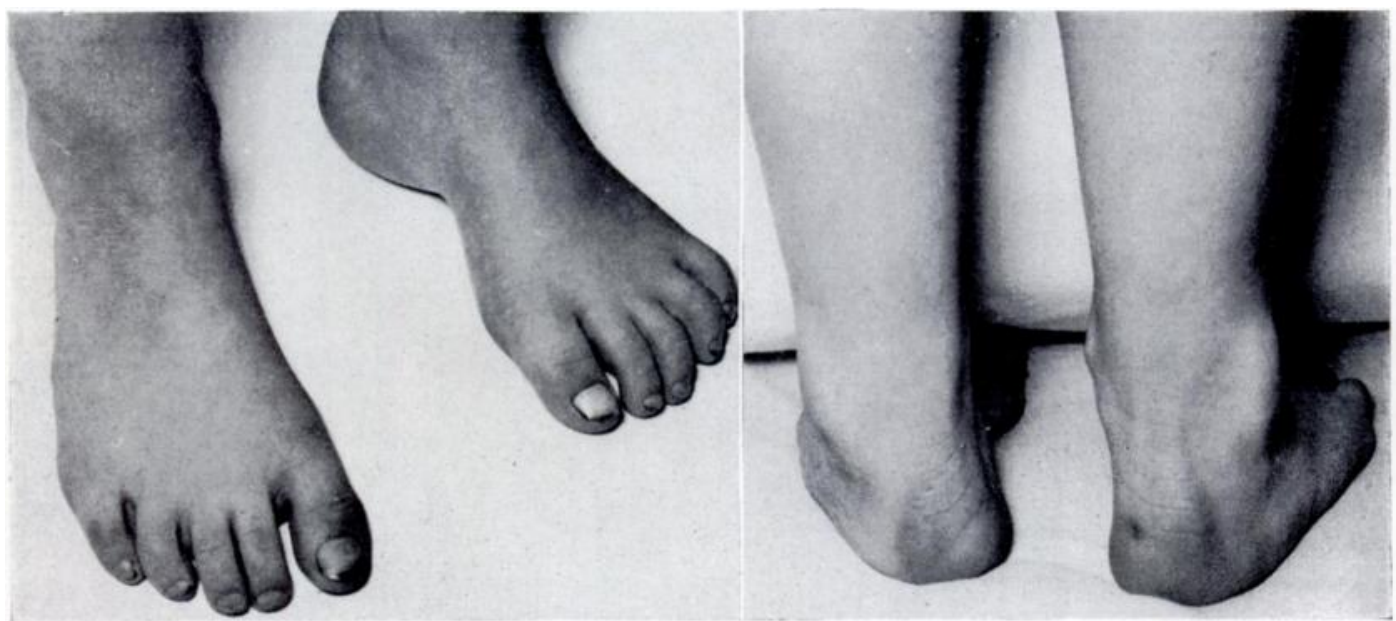

Fig. 4

Case 1-Pes cavus with early varus deformity complicating poliomyelitis in a boy of five.

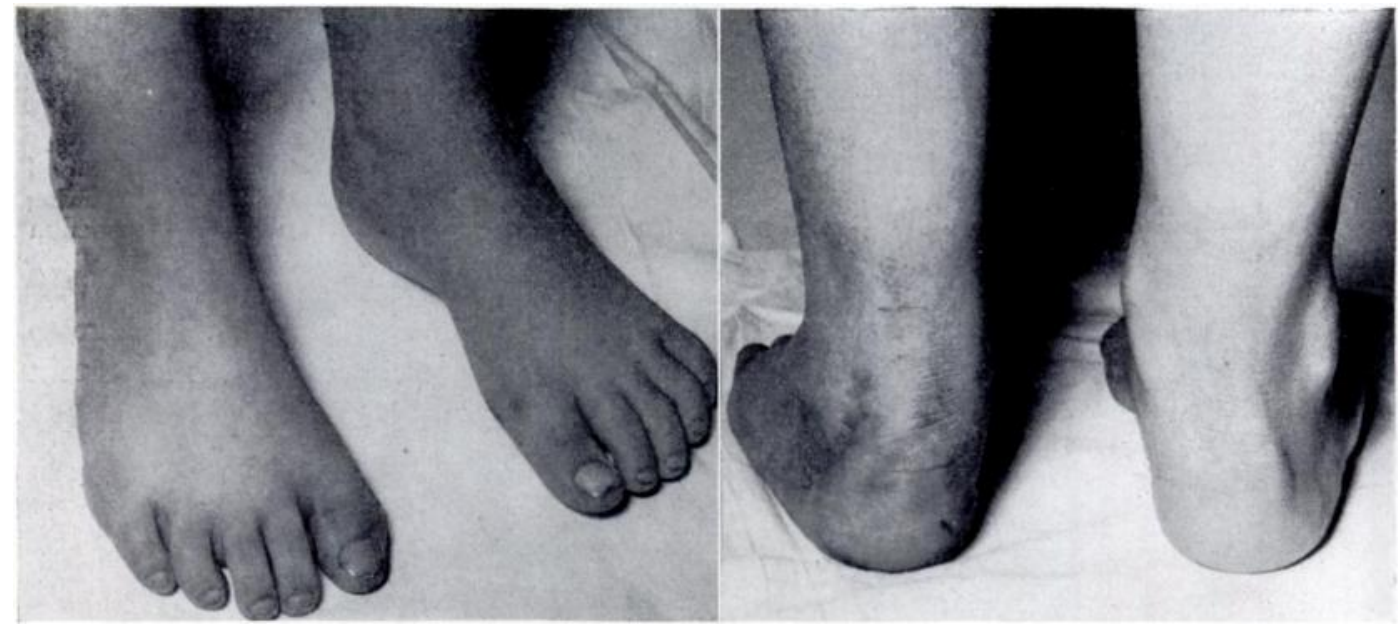

Fig. 5

Case 1-Nine months after osteotomy of left calcaneum. Heel deformity corrected and arch lower.

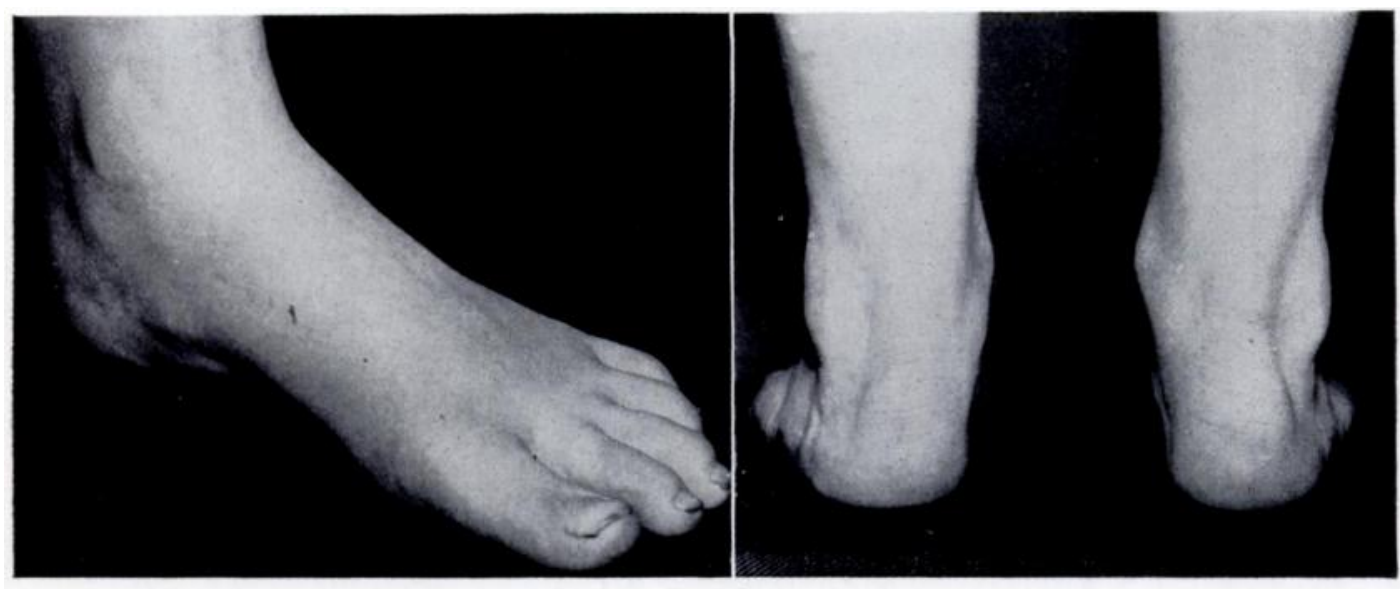

Fig. 6

Case 1-Three years after operation. Foot virtually normal and toes straight.

THE JOURNAL OF BONE AND JOINT SURGERY 


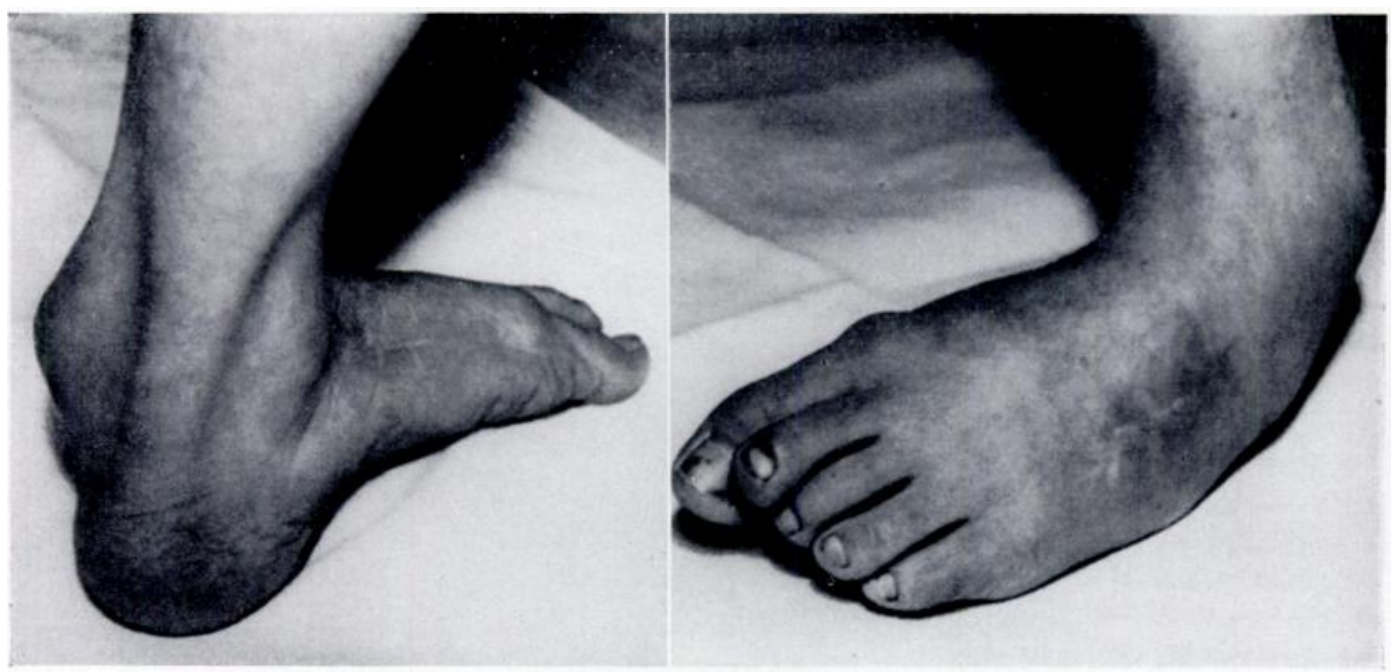

Fig. 7

Case 2-Deformity of foot in a boy of six, three years after accidental division of both peroneal tendons and a year after transplantation of tibialis anterior to base of fourth metatarsal.

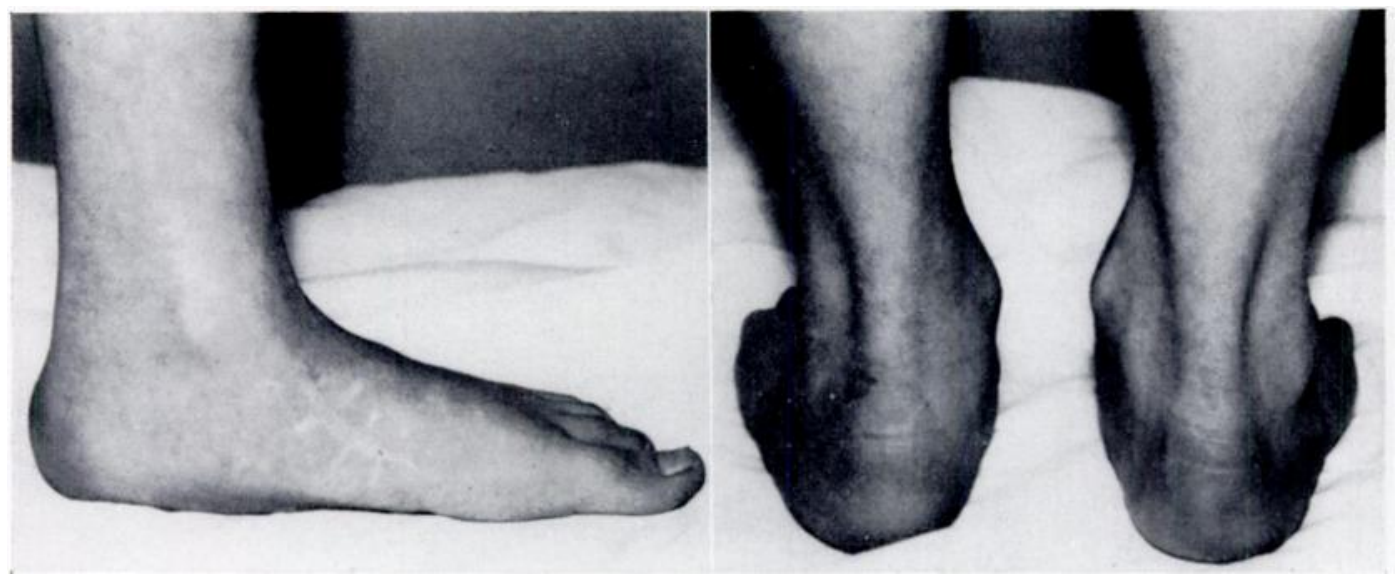

FIG. 8

Case 2-The same foot a year after removal of a lateral wedge from the calcaneum.

at this stage to be sure that the varus deformity has been properly corrected and that the heel is in a neutral or even slightly valgus position.)

\section{DISCUSSION}

An early effect of the operation is that walking and shoe wear are remarkably improved. With the varus deformity of the heel corrected, the forefoot gradually follows and the whole foot becomes plantigrade. With certain exceptions that will be mentioned later, relapse is rare and steady improvement takes place provided that the heel has been fully corrected (Figs. 4 to 12).

The principle underlying this type of correction was well illustrated in a boy of three, first seen eight months after irreparable division of both peroneal tendons. Transplantation of the tibialis anterior to the base of the fourth metatarsal two years later, when varus was already well established, failed to halt the progress of the deformity, which was severe at the age of six (Fig. 7). Osteotomy of the calcaneum was performed, and, with the heel squarely on the ground, progressive improvement took place with weight bearing (Fig. 8). 


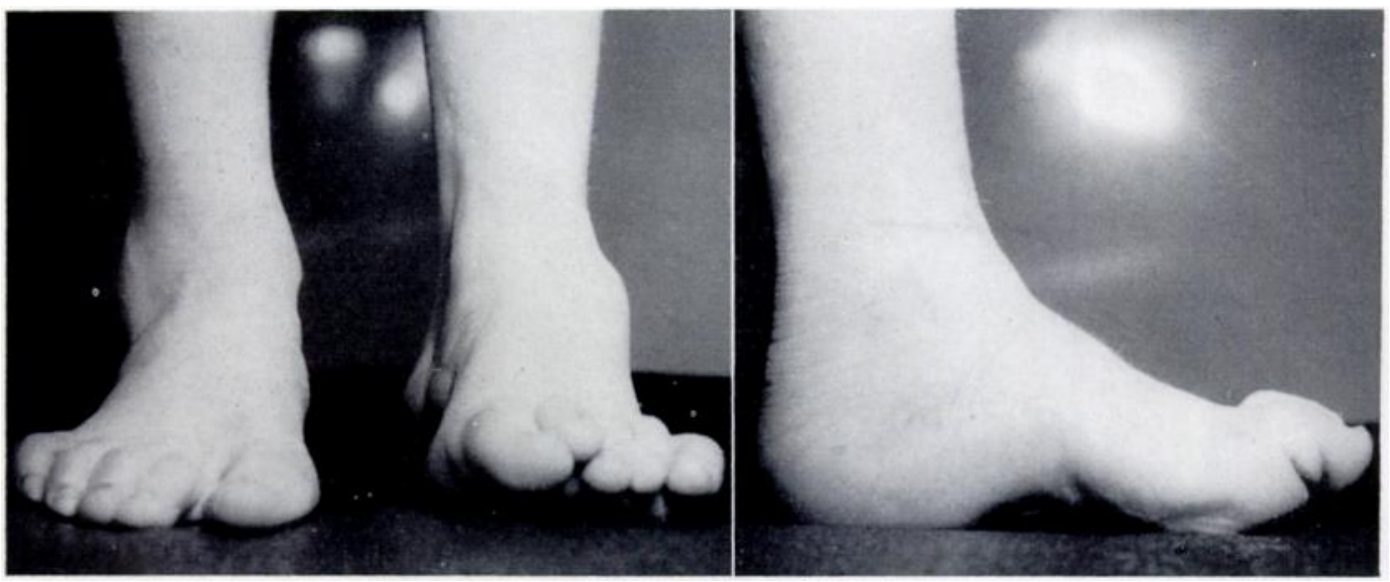

FIG. 9

Case 3-Recurrent cavo-varus deformity in a boy aged twelve, two years after the performance of a Steindler operation. (Same patient as in Figure 1.)

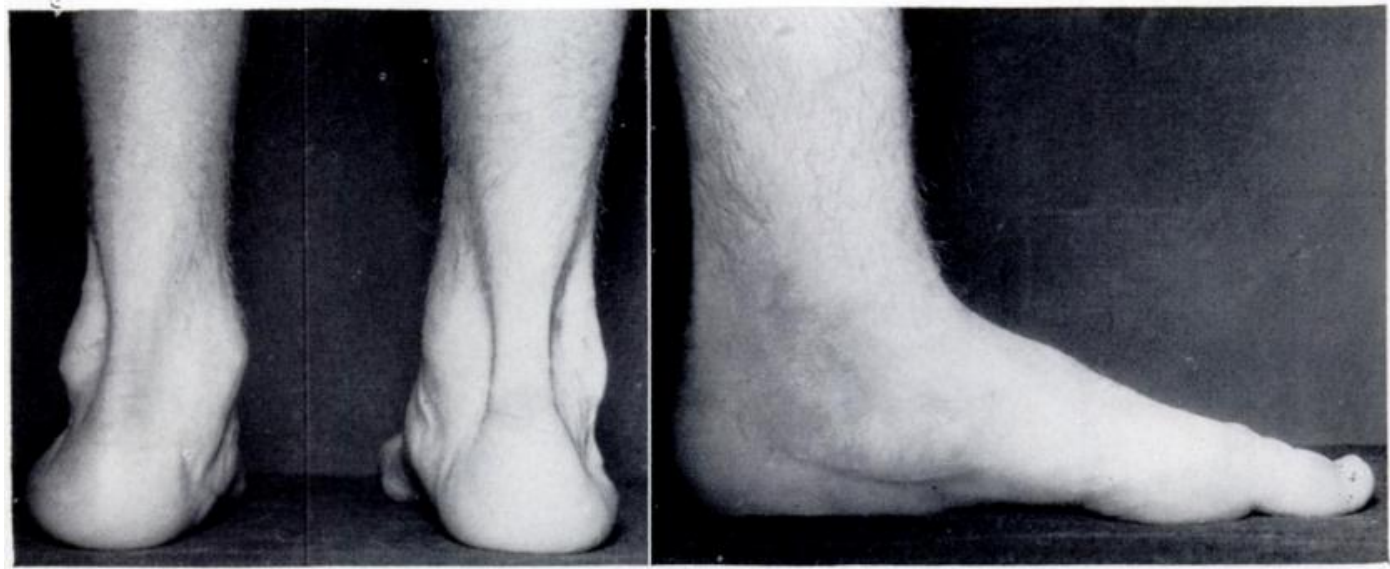

Fig. 10

Case 3-The same patient four years after wedge osteotomy of the calcaneum. The toes were not operated upon, and correction of the clawing has been brought about simply by weight bearing after correction of the heel.

Failure to correct fully the varus deformity of the heel will inevitably lead to recurrence or progress of the initial deformity (Fig. 9), and this explains the high incidence of recurrence after the older types of operation.

Since it was first performed in May 1952 this operation has now been undertaken sixtythree times in forty-one children aged from three to sixteen years. In all the patients the improvement, not only in gait and shoe wear, but also in the dropping of the forefoot and clawing of the toes, has been striking. The early promise has been so well fulfilled by the passage of time that it seems unnecessary to perform any other operation for established pes cavus. In patients presenting early with a high arch only and no varus of the heel, a plantar fasciotomy alone is indicated.

In a few cases it has been necessary to repeat the operation either because complete correction was not obtained at the first operation or because of real recurrence. The reason for recurrence may in some instances be the primary tendency, but muscular imbalance seems to be an important cause because it is particularly in cases of poliomyelitis and spina bifida that one encounters such recurrence. This was well illustrated in a patient of seven, with 


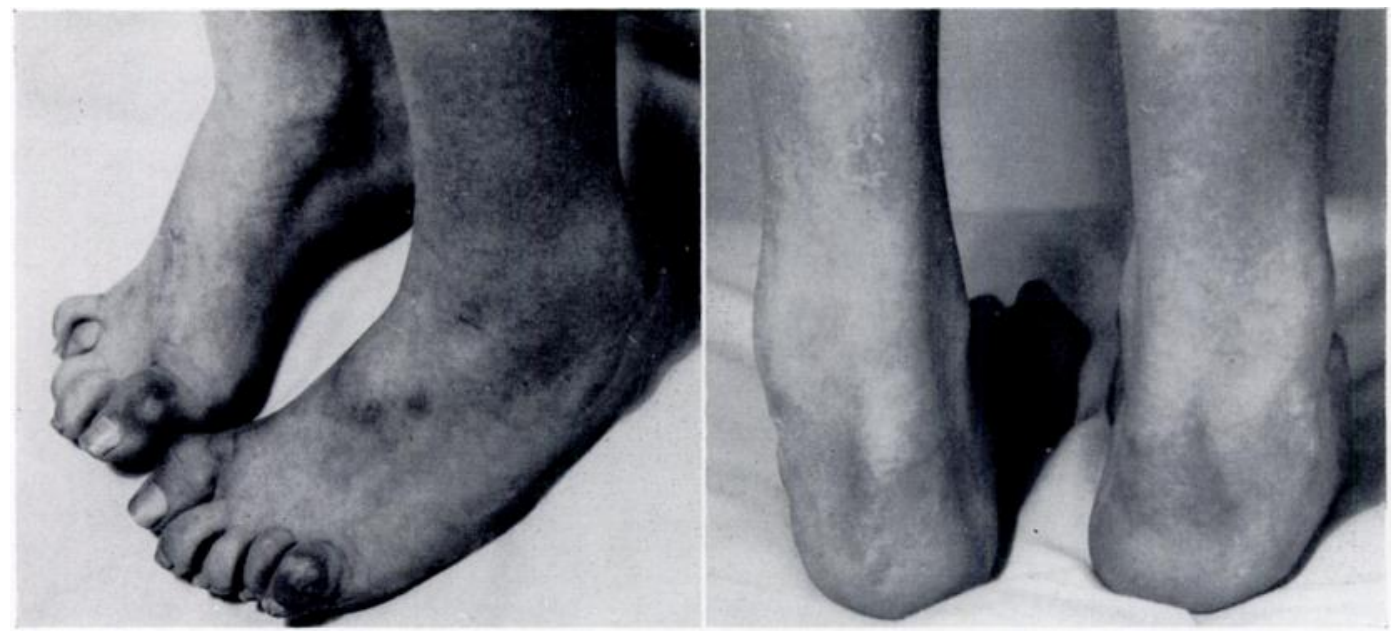

Fig. 11

Case 4-Severe deformity of feet in a girl of sixteen.

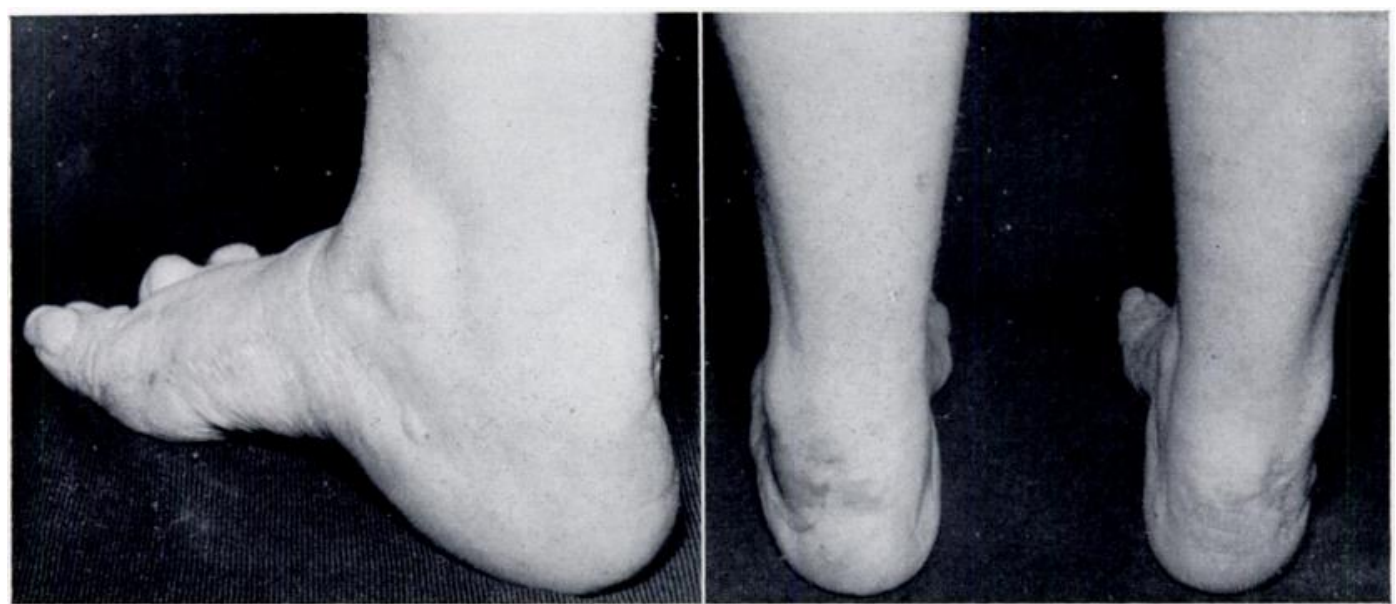

Fig. 12

Case 4-Two years after correction of the varus of the heel together with multiple filleting and arthrodesis of the toes.

marked varus of the heel after poliomyelitis. Good correction was obtained but, two years later, a second osteotomy was necessary because varus had recurred and, even after that, there was further recurrence, which was dealt with by transplanting the tibialis anterior to overcome the relative weakness of the evertors.

Recurrence occurred also in one patient with spina bifida who suffered infection of the calcaneum after the operation. A persistent sinus cleared up after removal of a sequestrum. There was then still some varus of the heel and it was rather small and did not come properly to the ground. Three years after the original operation the varus deformity was corrected by inserting a bone wedge into the inner side of the calcaneum, which had the effect of increasing the height of the heel and at the same time improving the deformity.

In six heels the operation was repeated at an interval varying from six to eighteen months after the original operation because there was some varus deformity, probably because the initial wedge had been too narrow.

Even in older children, with well established bony deformity of the forefoot, quite appreciable flattening of the longitudinal arch can be demonstrated some time after correction

VOl. 41 B, NO. 1, FEBRUARY 1959 
of the heel (Figs. 11 and 12). The degree of correction seen in Figure 12 is better than average, and the extent of falling of the arch which takes place depends on the age at the time of operation and on the strength of the bones. In boys, with rather stronger bones than in girls, one does not expect to see so much change in the cavus element. Nevertheless correction of the heel overcomes the important problem of excessive wear of the outer sides of the shoes, and also allows the toes to straighten out if they are malleable. The subjective improvement is much greater than the objective because the feet are properly balanced.

In patients with pes cavus one seldom encounters real contracture of the calcaneal tendon. If such contracture is present it must be dealt with first by a separate operation, before correction of the cavus deformity.

In adults with a high fixed arch, gross varus of the heel and forefoot and clawing of the toes, good correction can be obtained by the same means. A large lateral wedge is removed from the heel to correct inversion, and the plantar fascia is divided. The dropped and distorted forefoot can then be brought up to full correction by taking an appropriate wedge from the tarso-metatarsal region. It must be appreciated, however, that to achieve sound fusion at this site takes a good deal longer than is the case with a mid-tarsal wedge. This is a small price to pay for preservation of mid-tarsal-subtalar movement.

\section{SUMMARY}

1. A new surgical approach to the treatment of pes cavus is suggested. The operation consists in a subcutaneous division of the contracted plantar fascia and correction of the varus deformity of the heel by removing a wedge from its lateral aspect. It is submitted that, by approaching the deformity from behind and overcoming the varus of the heel, the foot is rendered plantigrade and that thereafter weight bearing exerts a corrective influence which results in progressive improvement of the deformity. The operation is essentially a prophylactic one and, for the best results, it should be performed before there is gross structural deformity and while active growth is still taking place.

2. Even in patients over the age of fourteen, improvement is obtained by doing nothing more than this simple operation. In the presence of fixed deformity of the forefoot, as encountered in older patients, inversion is corrected by removing a lateral wedge from the calcaneum and the cavus by taking a dorsal wedge from the tarso-metatarsal region. This has the double advantage of producing good correction of deformity, while at the same time preserving movement at the mid-tarsal-subtalar joint. Fixed clawing of the toes will require appropriate corrective treatment, but if the toes are malleable the simple effect of weight bearing on the plantigrade foot produces gradual correction.

\section{REFERENCES}

Dwyer, F. C. (1955): A New Approach to the Treatment of Pes Cavus. Sixième Congrès de Chirurgie orthopédique, Berne, 30 août-3 septembre 1954. Société Internationale de Chirurgie Orthopédique et de Traumatologie, p. 551. Bruxelles: Imprimerie Lielens.

Hallgrimsson, S. (1939): Pes Cavus, seine Behandlung und einige Bemerkungen über seine Ätiologie. Acta Orthopaedica Scandinavica, 10, 73.

Lambrinudi, C. (1932): Use and Abuse of Toes. Post-Graduate Medical Journal, 8, 459.

Steindler, A. (1921): The Treatment of Pes Cavus (Hollow Claw Foot). Archives of Surgery, 2, 325.

Todd, A. H. (1935): The Treatment of Pes Cavus. Proceedings of the Royal Society of Medicine (Section of Orthopaedics), 28, 117. 